\title{
Long-term light environment variability in Lake Biwa and Lake Kasumigaura,
} Japan: Modeling approach

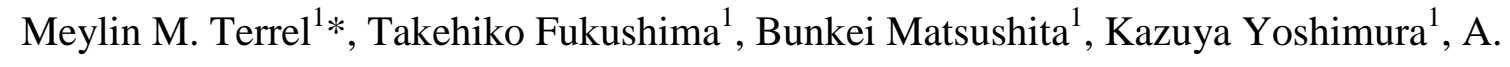
Imai $^{2}$

${ }^{1}$ Graduate School of Life and Environmental Sciences, University of Tsukuba

1-1-1 Tennoudai, Tsukuba, Ibaraki, 305-8572, Japan

E-mails:

mterrelg@ies.life.tsukuba.ac.jp

fukusima@sakura.cc.tsukuba.ac.jp

mbunkei@sakura.cc.tsukuba.ac.jp

kazuya_yoshimura@ies.life.tsukuba.ac.jp

${ }^{2}$ National Institute for Environmental Studies

16-2 Onogawa, Tsukuba, Ibaraki, 305-8506, Japan

E-mail: aimai@nies.go.jp

*Corresponding Author

E-mail: mterrelg@ies.life.tsukuba.ac.jp

"SCRIPTREVISION CERTIFICATION: This manuscript has been copyedited by Scriptrevision, LLC and conforms to Standard American English as prescribed by the Chicago Manual of Style. The Scriptrevision manuscript reference number is B428B618, which may be verified upon request by contacting admin@scriptrevision.com.” 


\title{
Long-term light environment variability in Lake Biwa and Lake Kasumigaura, Japan: Modeling approach
}

\begin{abstract}
Light environment variability was investigated in the two Japanese Lakes Biwa and Kasumigaura, which offer a broad range of optical conditions in the water bodies due to their diverse morphometries and limnological characteristics. To elucidate their light environments, Secchi depths (SDs) were connected with the long-term monitored datasets of concentrations of optically active substances (OASs) by using two approaches based on statistical and mechanistic models. The good estimation of the non-phytoplanktonic suspended solids (NPSS) concentration using a monthly factor $\delta$ (that represents the phytoplanktonic portion in total suspended solids) from a long-term analysis helped to develop robust models. Using the mechanistic model, the OAS contributions to SD can be understood and further investigated in detail than would be possible with the statistical approach, but on the other hand the statistical model presented better results in terms of SD prediction. From the analysis of OAS contributions to SD, it was clear that NPSS was the most influential component that controlled the light environments in the two lakes; in this respect, this study supports other studies showing the importance of the suspended inorganic particles as the main contributors to SD in inland waters. Using ANOVA we analyzed how specific inherent optical properties (SIOPs) might have changed spatially and temporally, indicating that the temporal (monthly) effect was primarily responsible for the loss of accuracy in the models. In addition, the ANOVA analysis suggested the grouping of data to improve the prediction performance of the statistical models. Finally, we concluded that the combination of the two models could lead to the most reliable results in terms of SD prediction and OAS contributions to SD at present.
\end{abstract}

Keywords Secchi depth, Chlorophyll-a, NPSS, DOC, optical properties

\section{Introduction}

Light penetration has important ecological and water quality implications, as it influences many aspects in lakes ecosystems such as primary production, species composition of phytoplankton, the depth distribution of submerged macrophytes and the heat budget of waterbodies (Reinart et al. 2003). Besides, studies provided evidence that the light environment can affect the bacterial numbers and composition e.g. decreasing the abundance of phototrophic microorganisms (Lear et al. 2009). Secchi depth (SD) is the most straightforward index to evaluate light penetration in aquatic ecosystems (Smith 
2001; Wetzel 2001). Hence it has the longest record of use in optical characterization, and remains the most commonly measured optical attribute (Effler et al. 2008).

Light field of inland waters are typically influenced by optically active substances (OASs) such as phytoplankton (represented by Chlorophyll-a: Chl-a), non-phytoplanktonic suspended solids (NPSS; e.g. mineral particles, dead organisms, decaying organic matter, zooplankton and other microbes) and colored dissolved organic matter (CDOM) that may be carried to the water by rivers from the surrounding land, or re-suspended from the lake bottom or produced in the lake (Reinart et al. 2003). In the last decades, many studies have derived relationships between OASs and SD by using two modeling approaches: a widely used statistical model (Jassby et al. 1999; Armengol et al. 2003; Effler et al. 2002; Zhang et al. 2006; Swan et al. 2007; Obrador \& Petrus 2008) and a model based on water optics theory. The latter had a further attempt because many considerations (e.g. delineation of the specific absorption and scattering roles played by each OAS) should be taken into account for its development (Effler et al. 2005; Pierson et al. 2005; Swift et al. 2006; Effler et al. 2008). A comparison between statistical and mechanistic models for SD prediction considering all OAS contributions has not been done so far. In addition, models that quantify all OAS contributions on SD are necessary for appropriate basin ecosystem restoration, and to establish reasonable expectations for related management efforts (Effler el al. 2008).

Statistical approaches based on single OAS, perform poorly in systems where variations in more than one OAS are important in regulating SD dynamics. For instance, Chl-a failed as the best predictor after a reduction of Chl-a concentration could not increase SD levels (Cooke et al. 1993). Later, in many productive inland waters, the suspended inorganic particles have been increasingly suspected to be the most influential substances that regulate light penetration (Davies-Colley et al. 1993; Effler and Perkins 1996; Jassby et al. 1999). More recently, the suspended inorganic particles were implied as the main contributors on SD by some studies using models based on water optics theory (Swift et al. 2006; Effler et al. 2008), but still some uncertainties related to the OAS optical properties remained in order to state them as the most significant substances (e.g. the absorption of the suspended inorganic particles and the variability of the scattering of phytoplankton remained the most understudied). The suspended inorganic particles may have autochthonous (e.g., chemical precipitation; Weidemann et al. 1985) and allochthonous origins (e.g. terrigenous; Nagai et al. 2001).

We undertook this study in two lakes in Japan, Lake Biwa (deep lake with a maximum 
112 depth $>100 \mathrm{~m}$ ) and Lake Kasumigaura (shallow lake with a maximum depth $<10 \mathrm{~m}$ ), 113 which offer a broad range of optical conditions within the water bodies due to their 114 diverse morphometries and limnological attributes. In both lakes, a range of optical 115 measurements have been taken occasionally in recent years. However, continuous 116 11-years and 19-years records of SD and OAS concentrations in Lakes Biwa and 117 Kasumigaura respectively, which provide a quantitative measure of long-term light 118 environment dynamics, are very important for developing robust models with high 119 reliability.

The objectives of this study included (a) understanding the long-term light environment variability in the lake ecosystems by evaluating a statistical and a mechanistic model to predict SD, and (b) quantifying each OAS contribution to SD (i.e. to elucidate the most influential substance that determines the light field in inland waters). As to the first objective, the merits and demerits for each model have been examined and discussed in the present paper, and a spatial and temporal analysis of the model performances has provided some hints about changes in the optical properties during the long-term periods that could improve the models. As to the second, the quantification of each OAS contribution is expected to contribute in a fundamental way to the management of water quality and ecosystem.

131

\section{Materials and methods}

Sites description and monitored data

Lakes Biwa and Kasumigaura are the first and second largest lakes in Japan, respectively (Table 1). Their water quality is a major concern since their waters are used for drinking, industrial, and agricultural purposes. Lake Biwa is geometrically divided into two parts, namely a northern and a southern basin, each with different characteristics. The northern basin is a pelagic zone that accounts for $90 \%$ of the total lake area (Belzile et al. 2002) and is therefore the main basin. In this analysis, we focused only on the northern basin (pelagic zone) because it contained a negligible amount of floating and submerged vegetation. In summer, the northern basin is thermally stratified, resulting in thermocline formation. The thermocline usually appears from May to November and has a great impact on material flow in the lake (Monomictic lake: Urabe et al. 1999), and consequently on the growth and the vertical distribution of primary producers. This basin 
Lake Kasumigaura has three basins (two large bays called Takahama-iri and Tsuchiura-iri, and a central basin) and is so shallow and flat that vertical stratification is easily destroyed by a moderately strong wind $\left(>5 \mathrm{~ms}^{-1}\right.$ : Fukushima and Muraoka 1981). After 1980, aquatic macrophytes disappeared from almost all regions. Lake Kasumigaura is considered to be eutrophic, because of high loads of nutrients and its shallow depth (Fukushima et al. 1996).

Several factors, such as long periods of observation at numerous stations distributed over the region, and monthly record-keeping offer a unique opportunity to improve our understanding of light field variability in these lakes (Fig. 1). A total of 9 lines are drawn across the northern basin of Lake Biwa at nearly uniform intervals from north to south, and 28 sampling stations are designated, based on 3 fixed points (eastern shore, center of lake, western shore) located on these lines (except for line 17 based on 4 points). In Lake Kasumigaura, 10 sampling stations were located in the bay areas and central basin. In this study, we chose April as the beginning of the year considering the vertical mixing regime and algae blooming outbreak. As the knowledge of the in-situ optical properties is very important for developing the mechanistic model, additional measurements, that include absorption and scattering coefficients, were carried out in 2009 and 2010 for the two lakes. For all measurements (long-term and additional measurements), SD were measured; water samples were collected from the water surface in Lake Biwa and taken using a column sampler (0-2 m depth) in Lake Kasumigaura. For the long-term measurements in Lake Kasumigaura, water samples were immediately filtered onto Whatman GF/F glass fiber filters. The Chl-a was extracted using methanol $(10 \mathrm{ml})$ at $3^{\circ} \mathrm{C}$ for 12 hours in a dark condition, then the extract was centrifugated at $3000 \mathrm{rpm}$ for 10 min and analyzed spectrophotometrically by SCOR-UNESCO (1966). Total suspended solids (TSS) concentrations were measured gravimetrically using pre-combusted Whatman $\mathrm{GF} / \mathrm{F}$ filters at $450^{\circ} \mathrm{C}$ for 4 hours. Dissolved organic carbon (DOC) concentrations were measured according to the high-temperature combustion method. Similarly, for all other measurements in the two lakes, the data specifications including measurement methodologies are described in Table 2. The estimation of NPSS concentration using a monthly factor $\delta$ (that represents the phytoplanktonic portion in TSS) based on the method of Gons et al. (1992) is explained in Appendix A (Online 
long-term periods are presented in Fig. 3. Regarding the optical measurements, the absorbance of the extracted Chl-a was measured at four wavelengths $(\lambda)$ : 750, 663, 645 and $630 \mathrm{~nm}$ using a spectrophotometer (UV-1700, Shimadzu, Tokyo, Japan); and the absorption of CDOM was measured from the filtered water using the same instrument. The absorption of NPSS was obtained after extraction of the pigments from the $0.7 \mu \mathrm{m}$ Whatman $\mathrm{GF} / \mathrm{F}$ filter using hot ethanol $\left(80 \%, 75^{\circ} \mathrm{C}\right)$ according to the quantitative filter technique (Mitchell 1990). In situ reflectance spectra were collected according to Method 1 of Mueller et al. (2000) for estimating the scattering coefficients based on an inversion of the bio-optical model (Yang et al. 2011).

Please insert Table 2 here

\section{Model development}

Several assumptions were made as follows. It was supposed that surface waters were well mixed by wind, and that the mixed layer was deeper than the SD. As a result, it was assumed that OAS concentrations were uniform in the layer from the surface to SD.

\section{Statistical model}

Multivariate linear regression analyses for the long-term datasets of the two lakes were performed by using $\mathrm{SD}^{-1}$ as a response variable and Chl-a $\left(\mu \mathrm{gl}^{-1}\right)$, NPSS $\left(\mathrm{mgl}^{-1}\right)$ and DOC $\left(\mathrm{mgl}^{-1}\right)$ concentrations as explanatory variables. The tested models with all possible combinations of variables (7 models) were evaluated using the Akaike's Information Criterion (AIC) to select the best prediction model.

\section{Mechanistic model}

The equations involved in this model were selected from the best currently available knowledge of water optics. Based on the contrast transmittance theory (Tyler 1968, Preisendorfer 1986), the following Secchi depth relation was developed:

$$
\mathrm{SD}^{-1}=\Gamma^{-1} \cdot\left[\overline{\overline{\mathrm{c}}}+\overline{\overline{\mathrm{K}}}_{\mathrm{d}}\right]
$$

where $\overline{\bar{c}}$ and $\overline{\bar{K}}_{d}$ are depth-averaged (from water surface to SD) beam and diffuse attenuation coefficients, respectively. Both describe spectrally averaged conditions weighted towards the wavelength-dependency of the human eye's photopic response and downwelling irradiance at the water surface (Preisendorfer 1986). The photopic function possesses a maximum around $555 \mathrm{~nm}$ and is near zero at the two ends of the visible spectrum. $\Gamma$ is a coupling constant that depends on variations in ambient conditions 
during measurements (Preisendorfer 1986). In this study, the value of $\Gamma$ for each specific system was estimated by adjusting its value to give the smallest root mean square error (RMSE) index, when the predicted reciprocals of Secchi depths $\left(\mathrm{SD}^{-1}\right)$ were compared to the measured $\mathrm{SD}^{-1}$. Beam attenuation coefficient $\mathrm{c}(\lambda)$ was expressed as the sum of absorption and scattering coefficients:

$$
c(\lambda)=a(\lambda)+b(\lambda)
$$

Absorption $\mathrm{a}(\lambda)$ and scattering $\mathrm{b}(\lambda)$ are inherent optical properties (IOPs) and therefore can be expressed as the sum of contributions by individual components (Mobley, 1994). Since there is no standard method for measuring the mass concentration of CDOM, it is conventionally measured as the absorption coefficient of CDOM at the reference wavelength $440 \mathrm{~nm}: \mathrm{a}_{\mathrm{CDOM}}(440)$ (Babin et al. 2003a).

$$
\mathrm{a}(\lambda)=\mathrm{a}_{\mathrm{w}}(\lambda)+[\text { Chla }] \cdot \mathrm{a}_{\mathrm{ph}}^{*}(\lambda)+[\text { NPSS }] \cdot \mathrm{a}_{\mathrm{NPSS}}^{*}(\lambda)+\mathrm{a}_{\mathrm{CDOM}}(440) \cdot \mathrm{a}_{\mathrm{CDOM}}^{*}(\lambda)
$$

and

$$
\mathrm{b}(\lambda)=\mathrm{b}_{\mathrm{w}}(\lambda)+[\text { Chla }] \cdot \mathrm{b}_{\mathrm{ph}}^{*}(\lambda)+[\mathrm{NPSS}] \cdot \mathrm{b}_{\mathrm{NPSS}}^{*}(\lambda)
$$

where the terms in brackets [Chla] and [NPSS] refer to the concentrations of Chl-a $\left(\mu \mathrm{gl}^{-1}\right)$ and NPSS $\left(\mathrm{mgl}^{-1}\right)$, respectively. $\mathrm{a}_{\mathrm{w}}(\lambda)$ is the absorption coefficient of pure water (Pope and Fry 1997), and $b_{w}(\lambda)$ represents the scattering by pure water (Morel 1974). $\mathrm{a}_{\mathrm{ph}}^{*}(\lambda), \mathrm{a}_{\mathrm{NPSS}}^{*}(\lambda)$, and $\mathrm{a}_{\mathrm{CDOM}}^{*}(\lambda)$ are the specific absorption coefficients for phytoplankton, NPSS and CDOM, respectively. $b_{\mathrm{ph}}^{*}(\lambda)$, and $b_{\mathrm{NPSS}}^{*}(\lambda)$ are the specific scattering coefficients for phytoplankton and NPSS, respectively. Similarly to Zhang et al. (2005), we related $\mathrm{a}_{\mathrm{CDOM}}(440)$ and DOC concentration linearly.

$$
\mathrm{a}_{\mathrm{CDOM}}(440)=\mathrm{a}^{+}(440) \cdot[\mathrm{DOC}]+e^{\prime}
$$

where [DOC] represents the concentration of DOC $\left(\mathrm{mgl}^{-1}\right)$. The slope $\mathrm{a}^{+}(440)$ and intercept $e^{\prime}$ represent the DOC-absorption coefficient and the constant background of uncolored DOC in surface waters, respectively. $\mathrm{a}^{+}(440)$ and $e^{\prime}$ have been obtained for the additional measurements in the two lakes (Table 3), and their average values in

Diffuse attenuation coefficient $\mathrm{K}_{\mathrm{d}}(\lambda)$ was estimated based on the relationship given by Kirk (1984).

$$
\mathrm{K}_{\mathrm{d}}(\lambda)=\frac{\left[\mathrm{a}(\lambda)^{2}+k_{\mu} \cdot \mathrm{a}(\lambda) \cdot \mathrm{b}(\lambda)\right]^{0.5}}{\mu_{0}}
$$


The coefficient $k_{\mu}$ was estimated from the following equation (Bowers et al. 2000)

$$
k_{\mu}=0.425 \cdot \mu_{0}-0.19
$$

where $\mu_{0}$ is the cosine of zenith angle of refracted solar photons, calculated from the solar zenith angle (SZA) using Snell's Law with the appropriate index of refraction for water and air. The SZA was calculated from date, time, and latitude using equations given in Kirk (1994b). The values of $\mu_{0}$ ranged between 0.440-0.708 and 0.738-0.939 for Lakes Biwa and Kasumigaura, respectively.

Estimation of specific inherent optical properties (SIOPs)

$\mathrm{a}_{\mathrm{ph}}^{*}(\lambda)$ was obtained by dividing the absorption due to phytoplankton by the Chl-a concentration (Fig. 2). Similarly, $\mathrm{a}_{\mathrm{NPSS}}^{*}(\lambda)$ was obtained by dividing the absorption due to non-phytoplanktonic particles by the NPSS concentration. The separation of phytoplankton and NPSS scattering $\left(b_{\mathrm{ph}}^{*}(\lambda)\right.$ and $\left.b_{\mathrm{NPSS}}^{*}(\lambda)\right)$ was based on the assumption that the contributions of scattering due to phytoplankton cells and NPSS are proportional to the ratios of their masses. A similar assumption but referring to backscattering was considered by Brando and Dekker (2003). As demonstrated in previous studies, $\mathrm{a}_{\mathrm{CDOM}}^{*}(\lambda)$ and $\mathrm{a}_{\mathrm{NPSS}}^{*}(\lambda)$ together with $\mathrm{b}_{\mathrm{NPSS}}^{*}(\lambda)$, could be fitted with an exponential wavelength function as described in Table 4.

Please insert Fig. 2 here

Please insert Table 4 here

For the long-term prediction of SD, all SIOPs obtained from the additional measurements conducted during 2009 and 2010 in the two lakes were used.

\section{OAS contributions to SD}

Long-term averaged OAS concentrations for the two lakes were used to investigate the OAS contributions to SD for both statistical and mechanistic models. First, we calculate the effect of pure water: in the mechanistic models this effect was evaluated by setting other OAS concentrations (Chl-a, NPSS, and DOC) equal to zero, while in the statistical models it was estimated from the intercept. Then, we evaluate the effect of the respective OASs by setting each long-term averaged concentration as the only input to the models. Using both models the obtained contribution of each OAS includes the water effect which needed to be subtracted. 
292 Spatial and temporal patterns of SD prediction performance

294 A three-factor ANOVA was applied to the ratios of measured vs. predicted $\mathrm{SD}^{-1}$ for the 295 long-term monitoring data to evaluate year, month and station effects on the predictive 296 ability of the two models. This procedure revealed how significantly the ratios differed 297 between stations and times.

$$
\text { ratio }=\frac{\mathrm{SD}_{\text {predicted }}^{-1}}{\mathrm{SD}_{\text {measured }}^{-1}}
$$

On the other hand, the excellent performance of the mechanistic model in estimating SD for the additional measurements using measured SIOPs, suggested that the assumption of constant SIOPs for the long-term prediction of SD was responsible for the results of lower performance. Then, an analysis of the spatial and temporal patterns of SD prediction using the mechanistic model was meaningful because the variation of the above ratio from the value of 1 could be attributed to the variation of SIOPs. In this way, ANOVA results obtained by this analysis provided perspective about how SIOPs varied spatially and temporally. Additionally, as the correlation coefficients of statistical models depend on the data, we tried to understand how the prediction of SD would be affected by different arrangements of data. In this regard, ANOVA results using the statistical model suggested a specific grouping of the datasets designed to improve the performance of this approach.

\section{Results}

313

Overview of SD and OAS long-term trends

In Lake Biwa, SD annual averages broadly increased from 5 to $6.7 \mathrm{~m}$ during the 10 years (1998-2007) and decreased to $6 \mathrm{~m}$ in 2008 (Fig. 3a). In contrast, SD annual averages in Lake Kasumigaura was $0.97 \mathrm{~m}$ in the late 1980s and then decreased to $0.46 \mathrm{~m}$ until 2005, and finally increased reaching $0.64 \mathrm{~m}$ in 2007 (Fig. 3e). Regarding the OAS concentrations, Chl-a and NPSS concentrations in Lake Biwa were generally stable for the long-term period with relatively high values in spring and higher and lower values in summer and winter, respectively (Fig. 3b, 3c). In Lake Kasumigaura, there is a moderate peak for Chl-a concentrations in 1995 and 1996 followed by steadily decrease over time to 2005, and finally rise to $77.1 \mu \mathrm{gl}^{-1}$ in 2007 (Fig. 3f). Figure 3g shows an increasing trend of NPSS concentrations until 2005 and decrease after that. DOC concentrations in both lakes (Fig. 3d, 3h) exhibited a tendency to increase gradually, presenting some peaks 
as in Lake Biwa (in 2000) and in Lake Kasumigaura (in 1990, 1995 and 2002).

Please insert Fig. 3 here

\section{Statistical model}

The results of the evaluation of univariate and multivariate linear regressions using AIC indicated that the model including all OAS concentrations as independent variables predicted $\mathrm{SD}^{-1}$ better than the others: AIC are -1812 and -9067 for Lake Biwa and Lake Kasumigaura, respectively.

Coefficients of the regression models were highly significant $(p<0.0001)$ except for the DOC coefficient for Lake Kasumigaura ( $p$-value=0.196). In addition, the model performance yielded better results for Lake Biwa $\left(R^{2}=0.70\right.$, RMSE $\left.=0.05 \mathrm{~m}^{-1}\right)$ than for Lake Kasumigaura $\left(R^{2}=0.62\right.$, RMSE $\left.=0.39 \mathrm{~m}^{-1}\right)$. A comparison between predicted and measured $\mathrm{SD}^{-1}$ for long-term datasets indicated a rather large scatter of the results (Fig. 4). The scatter plot of $\mathrm{SD}^{-1}$ prediction for Lake Biwa showed generally a straight line with a moderate amount of scatter (Fig. 4a). On the other hand, the plot for Lake Kasumigaura showed a relatively larger scatter, and the predicted $\mathrm{SD}^{-1}$ values at low observed $\mathrm{SD}^{-1}$ were much more closely to the fitted line than those at high observed $\mathrm{SD}^{-1}$ (Fig. 4b).

Please insert Fig. 4 here

\section{Mechanistic model}

The coefficients of determination $\left(R^{2}\right)$ for the additional measurements in Lake Biwa ( $R^{2}=0.87$ for Nov 9-10, 2009; $R^{2}=0.98$ for Feb 2-3, 2010) were higher than the ones obtained in Lake Kasumigaura $\left(R^{2}=0.79\right.$ for Sep 1 , 2009; $R^{2}=0.84$ for Dec 15, 2009). The results for the additional measurements were expected to be the optimal performance that could be achieved by this approach, because these datasets included measured SIOPs at each station.

The mechanistic model for long-term monitoring data showed higher performance for Lake Kasumigaura $\left(R^{2}=0.56\right.$ and RMSE $=0.50 \mathrm{~m}^{-1}$ using the SIOPs of Sep 1, 2009; $R^{2}=0.59$ and RMSE $=0.48 \mathrm{~m}^{-1}$ using the SIOPs of Dec 15, 2009) than for Lake Biwa $\left(R^{2}=0.50\right.$ and RMSE $=0.08 \mathrm{~m}^{-1}$ using the SIOPs of Nov 9-10, 2009, and $R^{2}=0.54$, $\mathrm{RMSE}=0.07 \mathrm{~m}^{-1}$ using the SIOPs of Feb 2-3, 2010). From these results applying the mechanistic model, only the best performance results in each lake (obtained using the SIOPs of Feb 2-3, 2010 and Dec 15, 2009 for Lakes Biwa and Kasumigaura, 
respectively) were considered for further analysis of the long-term predicted SD. The scatter plot of $\mathrm{SD}^{-1}$ prediction for Lake Biwa long-term dataset was generally straight, and the points lay fairly close to the 1:1 line (Fig. 5a). The scatter plot for Lake Kasumigaura long-term dataset using the mechanistic model showed a similar shape to the one using the statistical model, evidencing more crowded in the lower part of the plot than in the upper (Fig. 5b). Please insert Fig. 5 here

The analysis of long-term datasets gave very similar $\Gamma$ values, namely 9.8 for Lake Biwa and 10.1 for Lake Kasumigaura. In the case of the additional measurements, they differed between lakes, yielding (6.2-6.9) for Lake Biwa and (9.1-9.5) for Lake Kasumigaura. All $\Gamma$ values are within the neighborhood of reasonable estimate values $(\Gamma: 6-10)$ given by Preisendorfer (1986).

In Lake Biwa, the coefficients related to the water component were similar. The values were $0.040 \mathrm{~m}^{-1}$ and $0.055 \mathrm{~m}^{-1}$ for the statistical and mechanistic model respectively. As the water component is a constant value, the agreement of this coefficient between the two models is very important to give confidence to the applicability of the statistical models. Otherwise, a correction of the statistically obtained water coefficient is needed. This correction consists of the process of performing correlation analysis between $\mathrm{SD}^{-1}$ (excluding the water component) and other OAS concentrations. For instance, this correction was needed to be applied to the Lake Kasumigaura long-term dataset, where the value $0.055 \mathrm{~m}^{-1}$ obtained from the mechanistic model was used as a constant (Table 5). The coefficients of the statistical model for Lake Kasumigaura including the above-mentioned correction included showed that all regression model coefficients corresponding to the respective OAS concentrations were highly significant $(p<0.0001)$.

Please insert Table 5 here

The quantification of OAS contributions to $\mathrm{SD}^{-1}$ for the two lakes and the two models showed NPSS as the most influential factor responsible for $\mathrm{SD}^{-1}$ changes (Fig. 6). In Lake Biwa, NPSS accounted for the $34 \%$ and $35 \%$ of $\mathrm{SD}^{-1}$ by using the statistical and mechanistic model, respectively. In Lake Kasumigaura, NPSS contribution was higher than in Lake Biwa, accounting for the $43 \%$ and $75 \%$ of $\mathrm{SD}^{-1}$ with the statistical and mechanistic model, respectively. The correction of the water contribution by using the statistical model for Lake Kasumigaura was included in this figure. 
The ANOVA results in Table 6 showed a significant change in $\mathrm{SD}^{-1}$ prediction performance $(p<0.05)$ using the mechanistic model for all temporal and spatial effects (Year, month and station). Results obtained for the single factors highlighted the main influence of the month and year factors compared to the station factor in both lakes, revealing the monthly effect as the strongest effects: Lake Biwa (F=95.09), and Lake Kasumigaura $(F=69.49)$. The variation in the ratios of measured vs. predicted $\mathrm{SD}^{-1}$ estimated over years, months and stations using the mechanistic model are shown in Fig. 7. In addition, despite the less influential spatial effect in both lakes, certain patterns for stations A, B and C of Lake Biwa were noticed (Fig. 7c), where the prediction ratios of all C-stations were closer to unity in comparison to other stations.

Using the spatially, yearly and monthly grouping of long-term datasets of the two lakes, statistical models were developed. Their coefficients of determination $R^{2}$ are shown in Fig. 8. All models were found to be highly significant $(p<0.0001)$. In case of spatial grouping for Lake Biwa, we grouped stations A, B and C based on the ANOVA results showed in Fig. 7c. For Lake Biwa, the yearly arrangement mostly improved the statistical model performances, and the best results were obtained in the year $2003\left(R^{2}=0.82\right.$, RMSE $=0.04 \mathrm{~m}^{-1}$ ). For Lake Kasumigaura, the monthly grouping was the one which improved the statistical model performances, and the model of January yielded the best results $\left(R^{2}=0.84\right.$, RMSE $\left.=0.25 \mathrm{~m}^{-1}\right)$. Although the spatial grouping of datasets showed the lowest improvement in the statistical model performances of the two lakes (Fig. 8c), a very clear improvement due to the grouping of certain stations was obtained. This involved grouping the eastern shore stations (C-stations) for Lake Biwa, and grouping the stations located in the center of Lake Kasumigaura (stations 7, 8 and 9). In general, this kind of grouping analysis may therefore prove to be helpful for the planning of future monitoring and datasets arrangement e.g. identifying the best approach to obtain and arrange data for the application of SD models across defined transects (yearly/ 


\section{Discussion}

Performance of the models

In both lakes, the models built with long-term measurements could explain more than $62 \%$ of the observed $\mathrm{SD}^{-1}$ variations using the statistical model and more than $50 \%$ using the mechanistic one. The RMSE values for the statistical model were lower than the ones for the mechanistic model. The RMSE values together with the $R^{2}$ values indicate the stronger predictive ability of the statistical model over the mechanistic one. By examining the scatter plots of the prediction applying the two models to the Lake Kasumigaura long-term dataset (Fig. 4b and Fig. 5b), we found that for low observed $\mathrm{SD}^{-1}$, the predicted values were much more closely to the fitted line than those at high observed values. As a way of predicting $\mathrm{SD}^{-1}$ in Lake Kasumigaura, it appears that both models might work quite well for low $\mathrm{SD}^{-1}$, but not efficient for high values. Compared to previous studies, our statistical model gave better predictions than those by Effler et al. (2008), which correlated SD vs Chl-a of 40 years data in Lake Onondaga, obtaining a performance of $R^{2}=0.43$. Our mechanistic model was also found to give slightly better performance than previous studies. For example, using an additive semi-analytical model, Swift et al. (2006) obtained $R^{2}=0.49$ for data of 4 years in Lake Tahoe. The loss of accuracy (2-20\%) encountered in the results of both lakes for the additional measurements using the mechanistic model may be attributable to measurement errors caused by imperfect weather conditions, unstable illumination during measurements, instrument calibration problems, measurements errors in OAS concentrations, etc. Moreover, the mechanistic model for long-term monitoring datasets did not yield performance comparable to that for the additional measurement datasets, where the decreases in performance of about 30\% for long-term monitoring datasets could be attributed to the seasonal change in OAS vertical profiles, the change in SIOPs, etc. In addition, testing of the mechanistic model using SIOPs values at the additional measurements has shown that the model works well when SIOPs values from all sampling stations were averaged to one value, with a small loss of accuracy of $3 \%$ $\left(R^{2}=0.95\right.$ for Feb. $\left.2-3,2010\right)$ and $1 \%\left(R^{2}=0.83\right.$ for Dec. 15, 2009) for Lake Biwa and Lake Kasumigaura, respectively.

With regard to the applicability of the two models, both were found to be very useful for estimating the OAS contributions on the light field. The mechanistic model can explain better the respective optical factors determining the light field, but the statistical 
reason for its wide use. It was also found that the grouping of data improved statistical performance of the models although caution should be taken when using statistical models for analysis of OAS contributions to SD because the coefficient related to water may need to be corrected as in Lake Kasumigaura. The large number obtained for the water coefficient in Lake Kasumigaura (represented as the intercept in the statistical model) may be attributable to the large values of $\mathrm{SD}^{-1}$ in this lake. A comparison of the water coefficients between the two models could be used as a validation step for the statistical model. In this respect, we suggest the combination of the two models in order to get the most reliable results for SD prediction and OAS contributions to SD. The water coefficient in Lake Biwa $\left(0.040 \mathrm{~m}^{-1}\right.$ and $0.055 \mathrm{~m}^{-1}$ for the statistical and mechanistic model respectively) are also comparable to those obtained using statistical models by Obrador and Petrus (2008) and Armengol et al. (2003), which were $0.040 \mathrm{~m}^{-1}$ and 0.034 $\mathrm{m}^{-1}$ respectively. Furthermore, the model coefficients obtained statistically by Peng and Effler (2005) for the Finger Lakes in New York (Chl-a coefficient: 0.014 and Tr coefficient: 0.04 ) had a good agreement with the following statistical model coefficients in Table 5: Chl-a coefficient for Lake Biwa (0.0137) and the Tr coefficient for Lake Kasumigaura (0.04).

A simple statistical SD model (considering all OAS concentrations) could be the one including TSS instead of NPSS as one of its independent variables, which some previous papers have proposed (e.g. Armengol et al. 2003; Zhang et al. 2006; Devlin et al. 2008). However a comparison of the performance of the model using TSS instead of NPSS with our model applied to the long term-period showed that the model including TSS presented a loss of accuracy of $5 \%\left(R^{2}=0.65\right)$ and $34 \%\left(R^{2}=0.28\right)$ for Lake Biwa and Lake Kasumigaura, respectively. These results reflect the importance of the separation of NPSS from TSS, especially for Lake Kasumigaura. In the past, the estimation of NPSS concentrations has been limited by analytical shortcomings and quite complicated procedures. For example, Swift et al. (2006) evaluated a limited number of samples (30 samples) using individual particle analysis technique of scanning electron microscope interfaced with X-ray image analysis to produce a seasonally-varying estimate of the suspended inorganic particles. Effler et al. (2008) applied the same technique but only to 6 samples. In this regard, the way we estimate NPSS concentrations using the phytoplanktonic portion in TSS $(\delta)$ obtained from a long-term analysis has the advantage of being simple and rather accurate. Given the importance of NPSS estimation, we tested the model performance applying a single $\delta$ value (yearly average), and results showed a loss of accuracy of about $6 \%$ in both lakes, indicating the importance of monthly change in $\delta$ values on SD prediction. 
513 OAS contributions to SD

514 NPSS has been identified to be the most influential component that governs the light 515 environment in the two lakes. Our result coincides with Swift et al. (2006), in which a 516 semi-analytical model was developed to predict SD in very clear waters (SD in the range 517 of $15-40 \mathrm{~m}$ ); they also concluded that the suspended inorganic particles dominated the 518 light environment for most of the year. In addition, Effler et al. (2008) showed that the 519 suspended inorganic particles played a critical role in influencing important features of 520 the lake's optical regime. It is worth noting that Lake Biwa and Lake Kasumigaura 521 differed in the second most important contributor to SD. At Biwa it was DOC while in 522 Kasumigaura it was Chl-a.

523 The high values of NPSS in Lake Biwa were probably caused by input of terrigenous particles through river water, which was due to snow melting in spring, rainfall in early summer, and typhoons in autumn (Nagai et al. 2001). In addition, re-suspension of sediments was the source of NPSS in winter due to internal waves caused by winds (Murase et al. 2005). In Lake Biwa DOC co-varied with SD ${ }^{-1}$ (Fig. 3d). This correlation suggests the importance of this substance on controlling water clarity.

Despite the eutrophic nutrient status of Lake Kasumigaura, the high concentration of NPSS seemed to restrict the light availability (Fig. 3e). Therefore, PSS in Lake Kasumigaura was inversely related to NPSS from 1997 to 2007 (PSS=-0.4655 NPSS + 21.71, $p<0.0001)$. The higher NPSS and lower PSS result principally from strong re-suspension of bottom sediment possibly attributed to water turbulence. Regarding DOC in Lake Kasumigaura, the unclear influence reflected in its annual trend (Fig. 3h) confirmed the low contribution on SD obtained by the mechanistic model.

Limitations of the mechanistic approach

538 It is a difficult task to measure SIOPs, and at present this difficulty is considered to be an 539 important shortcoming for developing the mechanistic model. From the ANOVA results, 540 it was possible to get some idea about how SIOPs may have changed spatially and 541 temporally, so we might expect the seasonal variability in SIOPs to be the most important 542 cause for the loss of accuracy in modeling, and conversely the spatial effect to be the less 543 influential. Hence further study of the long-term variability of optical properties should 544 be included in the ongoing research effort to estimate SIOPs in inland waters (e.g. 545 Campbell et al. 2010; Ambarwulan et al. 2010). On the other hand, the loss of accuracy in 546 modeling SD was higher in summer months, specifically in August-September in Lake 547 Biwa (Fig. 7b) and July-August in Lake Kasumigaura (Fig. 7e), which may be the result 548 of increasing Chl-a and NPSS concentrations. In Lake Kasumigaura, additional scatter 
was found in spring months, specifically in April and June (Fig. 7e), which could be explained by blooming of diatoms (e.g. Cyclotella). These two analyses suggest the possibility of considering both temporal SIOPs characteristics and seasonal change in OAS concentrations in the long-term SD prediction models.

To test the assumption of vertically uniform OAS concentrations, we tried using the measurements of diffuse attenuation coefficient $\mathrm{K}_{\mathrm{d}}$ in both lakes at the additional measurement campaigns. $\mathrm{K}_{\mathrm{d}}$ values were determined from radiometric measurements (irradiances) located above the surface and at various depths using a Satlantic hyperspectral radiometer with a StorX data logger system. These limited data of the vertical changes gave us an idea on what may occur vertically. For example, 25 stations in Lake Kasumigaura presented a small vertical change that could be easily ignored $\left(K_{d}=2.8 \pm 0.42\right)$; but for 3 stations in Lake Biwa, the vertical change appeared important to be considered $\left(\mathrm{K}_{\mathrm{d}}=0.27 \pm 0.12\right)$. This analysis revealed that the OAS concentrations estimated from surface water samples in Lake Biwa were underestimated. These underestimated OAS concentrations could be counted as uncertainties for the model inputs that would lead to an overestimation of SD values, and hence affect further analysis of each OAS influence on SD. At present, the limited data are insufficient to draw conclusions regarding how greatly the vertical profiles of OASs influence the SD prediction in Lake Biwa, but these shortcomings in measurements could be overcome through future monitoring that considers the vertical profiles in time and space.

Management implications for increasing SD

Management actions derived from this study focus on NPSS reduction to result in (aquatic macrophytes) may reduce sediment re-suspension significantly (Vermaat et al. 2000). Thus through their effects on re-suspension, macrophytes should also affect the release of phosphorus from the sediment (Horppila and Nurminen 2003), regulating phytoplankton biomass. In order to reduce pollutant loadings from their catchment areas, inflow from watersheds should be managed. For example, pre-sedimentation ponds attached to the lake (NAIKO) are believed to retain allochthonous suspended inorganic particles, lowering the amount of their entry to the lake (Nakamura et al. 2000).

\section{Conclusions}

582

583 Two types of predictive models relating SD with OASs were compared in this study and they did capture SD variability quite well. In addition, the two models provided valuable information of how the water components affected water transparency. By developing the 
586

587

588

589

590

591

592

593

594

595

596

597

598

599

600

601

602

603

604

605

606

607

608

609

610

611

612

613

614

615

616

617

618

619

620

621

622

mechanistic model, each OAS contribution on SD can be understood and investigated in greater detail than would be possible with the statistical model. The mechanistic model provided insights into the control of factors that influence decisions regarding where and how the reduction of OASs should be allocated for maximal effect.

We have found that NPSS is the most important OAS in controlling the light penetration in Lakes Biwa and Kasumigaura. For instance, the extent of light penetration would be negligibly influenced by reduction of nutrients in the two lakes, where reduction of NPSS may be a more appropriate management strategy to achieve increases on SD. Additionally, this study supports other studies about the importance of suspended inorganic particles as the main contributors on SD in inland waters suggesting that further studies would be worthwhile to characterize the different sources of the suspended inorganic particles and to account for the different mechanisms occurring within the water such as mixing events, wave action, re-distribution of sediments, and so on.

There is still room for improvement of mechanistic models, which at present are not generally applied in practice because of optical measurement constraints and complexity. In addition, between temporal and spatial characteristics on SIOPs, we conclude that temporal characteristics on SIOPs will be needed in order to optimize the mechanistic model. On the other hand, when the statistical approach is used, we strongly recommend enhancing its performance by arranging the datasets into groups and for its application the coefficient related to water should be confirmed to be reasonable. A validation step and a correction process related to the water coefficient were suggested for the statistical model. Finally, with regard to the applicability of the models, we have concluded that the combination of the two models could lead to the most reliable results available at present to predict SD and the various contributions of OASs to SD.

\section{Acknowledgments}

This research was supported by "Global Environment Research Fund by the Ministry of Environment Japan” B-0909. We express our thanks to all members involved in this project.

\section{References}

Ambarwulan W, Salama MS, Mannaerts CM, Verhoef W (2010) Estimating specific inherent optical properties of tropical coastal waters using bio-optical model inversion and in-situ measurements: case of the Berau estuary, Indonesia. Hydrobiologia, Online First, 3 Oct 2010. DOI: 10.1007/s10750-010-0473-7 
Armengol J, Caputo L, Comerma M, Feijoó C, García JC, Marcé1 R, Navarro E, Ordoñez J (2003) Sau reservoir's light climate: relationships between Secchi depth and light extinction coefficient. Limnetica 22:195-210

Babin M, Stramski D, Ferrari GM, Claustre H, Bricaud A, Obolensky G, Hoepffner N (2003a) Variations in the light absorption coefficients of phytoplankton, non-algal particles, and dissolved organic matter in coastal waters around Europe. Journal of Geophysical Research. doi: 10.1029/2001JC000882

Belzile C, Vincent WF, Kumagai M (2002) Contribution of absorption and scattering to the attenuation of UV and photosynthetically available radiation in Lake Biwa. Limnol. Oceanogr. 47(1):95-107

Bowers DG, Harker GEL, Smith PSD, Tett P (2000) Optical properties of a region of freshwater influence (The Clyde Sea). Estuarine, Coastal and Shelf Science 50:717-726

Brando VE, Dekker AG (2003) Satellite hyperspectral remote sensing for estimating estuarine and coastal water quality. IEEE Transactions on Geoscience and Remote Sensing 41:1378-1387

Campbell G, Phinn SR, Daniel P (2010) The specific inherent optical properties of three sub-tropical and tropical water reservoirs in Queensland, Australia. Hydrobiologia, Online First, 25 Sep 2010. DOI 10.1007/s10750-010-0476-4

Cooke GD, Welch EB, Peterson SA, Newroth PR (1993) Restoration and management of lakes and reservoirs. Second Ed., Lewis Pub. 548 p.

Davies-Colley RJ, Vant WN, Smith DG (1993) Colour and Clarity of Natural Waters. Ellis Horwood, New York. 310 p.

Devlin MJ, Barry J, Mills DK, Gowen RJ, Foden J, Sivyer D, Tett P (2008) Relationships between suspended particulate material, light attenuation and Secchi depth in UK marine waters. Estuarine, Coastal and Shelf Science 79:429-439

Effler SW, Perkins MG (1996) An optics model for Onondaga Lake. Lake and Reservoirs Management 12:115-125

Effler SW, Perkins MG, Ohrazda N, Matthews DA, Gelda R, Peng F, Johnson DL, Stephczuk CL (2002) Tripton, transparency and light penetration in seven New York reservoirs. Hydrobiologia 468:213-232

Effler SW, Gelda RK, Perkins MG, O'Donnell DM (2005) Modeling light attenuation, secchi disk, and effects of tripton in Seneca River, New York, USA. J. Am. Water Resource Association 41:971-984

Effler SW, Gelda R, Perkins MG, Peng F, Hairston NG, Jr, Kearns CM (2008) Patterns and modeling of the long-term optics record in Onondaga Lake, New York. Fundamental and Applied Limnology 172(3):217-237 
660

661

662

663

664

665

666

667

668

669

670

671

672

673

674

675

676

677

678

679

680

681

682

683

684

685

686

687

688

689

690

691

692

693

694

695

696

Fukushima T, Muraoka K (1981) Current and vertical mixing in a shallow lake. Verhandlungen Internationale Vereinigung Limnologie 21:141-149

Fukushima T, Park J, Imai A, Matsushige K (1996) Dissolved organic carbon in eutrophic lakes; dynamics, biodegradability and origin. Aquatic Sciences 58 (2):139-157

Gege P (2004) The water color simulator WASI: An integrating software tool for analysis and simulation of optical in situ spectra. Computers and Geosciences 30 (5):523-532

Giardino C, Brando VE, Dekker AG, Strömbeck N, Candiani G (2007) Assessment of water quality in Lake Garda (Italy) using Hyperion. Remote Sensing of Environment 109:183-195

Gons HJ, Burger-Wiersma T, Otten JH, Rijkeboer M (1992) Coupling of phytoplankton and detritus in a shallow, eutrophic lake (Lake Loosdrecht, The Netherlands). Hydrobiologia 233 (1-3):51-59

Goto N, Kihira M, Ishida N (2008) Seasonal distribution of photosynthetically active phytoplankton using pulse amplitude modulated fluorometry in the large monomictic Lake Biwa, Japan. Journal of Plankton Research 30:1169-1177

Havens KE, Fukushima T, Xie P, Iwakuma T, James RT, Takamura N, Hanazato T, Yamamoto $\mathrm{T}$ (2001) Nutrient dynamics and the eutrophication of shallow lakes Kasumigaura (Japan), Donghu (P.R.China), and Okeechobee (USA). Environmental Pollution 111:263-272

Horppila J, Nurminen L (2003) Effects of submerged macrophytes on sediment resuspension and internal phosphorus loading in Lake Hiidenvesi (southern Finland). Water Research 37:4468-4474

Jassby AD, Goldman CR, Reuter JE, Richards RC (1999) Origins and scale dependence of temporal variability in the transparency of Lake Tahoe, California-Nevada. Limnology and Oceanography 44:282-294

Kagami M, Gurung TB, Yoshida T, Urabe J (2006) To sink or to be lysed: contrasting fate of two large phytoplankton species in Lake Biwa. Limnology and Oceanography 51:2775-2786

Kirk JTO (1984) Dependence of relationship between inherent and apparent optical properties of water on solar altitude. Limnology and Oceanography 29(2):350-356

Kirk JTO (1994b) Light and photosynthesis in aquatic ecosystems, 2nd ed. Cambridge Univ. Press.

Lear G, Turner S, Lewis GD (2009) Effect of light regimes on the utilisation of an exogenous carbon source by biofilm bacterial communities. Aquatic Ecology 43: 207-220 
697

698

699

700

701

702

703

704

705

706

707

708

709

710

711

712

713

714

715

716

717

718

719

720

721

722

723

724

725

726

727

728

729

730

731

732

733

Mitchell BG (1990) Algorithms for determining the absorption coefficient of aquatic particulates using the quantitative filter technique (QFT). Proc. SPIE 1302:137

Mobley CD (1994) Light and water: radiative transfer in natural waters. Academic Press, San Diego.

Morel A (1974) Optical properties of pure sea water. Optical aspects of oceanography. London, U.K.: Academic

Mueller J L, Davis C, Arnone R, Frouin R, Carder K, Lee Z P (2000) Above-water radiance and remote sensing reflectance measurements and analysis protocols. Greenbelt, Maryland: National Aeronautical and Space Administration, Ocean Optics protocols for Satellite Ocean color sensor validation Revision 2:98-107

Murase J, Sakai Y, Kametani A, Sugimoto A (2005) Dynamics of methane in mesotrophic Lake Biwa, Japan. Ecological Research 20:377-385

Nagai M, Sugiyama M, Hori T (2001) Environmental chemistry of rivers and lakes, Part VII. Fractionation by calculation of suspended particulate matter in Lake Biwa into three types of particles of different origins. Limnology 2:147-155

Nakamura K, Morikawa T, Shimatani Y (2000) Pollutants control by the artificial lagoon. Environment System Research JSCE 28:115-123 (in Japanese)

Nusch EA (1980) Comparison of different methods for chlorophyll and phaeopigment determination. Arch. Hydrobiol. Beih. Ergebn. Limnol. 14:14-36

Obrador B, Pretus JL (2008) Light regime and components of turbidity in a Mediterranean coastal lagoon. Estuarine, Coastal and Shelf Science 77:123-133

Oyama Y, Matsushita B, Fukushima T, Matsushige K, Imai A (2009) Application of spectral decomposition algorithm for mapping water quality in a turbid lake (Lake Kasumigaura, Japan) from Landsat/TM data. ISPRS J. Photogrammetry Remote Sensing 64:73-85

Peng F, Effler SW (2005) Inorganic tripton in the Finger Lake of New York: importance to optical characteristics. Hydrobiologia 543:259-277

Pierson DC, Kratzer S, Strombeck N, Hakansson B (2005) Relationship between the attenuation of downwelling irradiance at $490 \mathrm{~nm}$ with the attenuation of PAR in the Baltic Sea. Remote Sensing of Environment 112:668-680

Pope RM, Fry ES (1997) Absorption spectrum (380-700 nm) of pure water. II. Integrating cavity measurements. Applied Optics 36(33):8710-8723

Preisendorfer RW (1986) Secchi disk science: Visual optics of natural waters. Limnology and Oceanography 31(5):909-926

Reinart A, Herlevi A, Arst H, Sipelgas L (2003) Preliminary optical classification of lakes and coastal waters in Estonia and South Finland. Journal of Sea Research 49:357-366 
Reinart A, Paavel B, Pierson D, Stroembeck N (2004) Inherent and apparent optical properties of Lake Peipsi, Estonia. Boreal Environment Research 9:429-445

SCOR-UNESCO (1966) Determination of photosynthetic pigments in seawater. Monographs on Oceanographic Methodology, UNESCO, Paris.

Smith DG (2001) A protocol for standardizing Secchi disk measurements, including use of a viewer box. Lake and Reservoir Management 17:0-96

Swan BK, Reifel KM, Tiffany MA, Watts JM, Hurlbert SH (2007) Spatial and temporal patterns of transparency and light attenuation in the Salton Sea, California, 1997-1999. Lake and Reservoir Management 23:653-662

Swift TJ, Perez-Lozada J, Schladow SG, Reuter JE, Jassby AD, Goldman CR (2006) Water clarity modeling in Lake Tahoe: linking suspended matter characteristics to Secchi depth. Aquatic Sciences 68:1-15

Tyler JE (1968) The Secchi disc. Limnol. Oceanogr. 13:1-6

Urabe J, Sekino T, Nozaki K, Tsuji A, Yoshimizu C, Kagami M, Koitabashi T, MiyazakiT, Nakanishi M (1999) Light, nutrients and primary productivity in Lake Biwa: An evaluation of the current ecosystem situation. Ecological Research 14:33-242

Vermaat JE, Santamaria L, Roos PJ (2000) Water flow across and sediment trapping in submerged macrophyte beds of contrasting growth form. Arch. Hydrobiol. 148:549-562

Weidemann AD, Bannister TP, Effler SW, Johnson DL (1985) Particulate and optical properties during $\mathrm{CaCO} 3$ precipitation in Otisco Lake. Limnology and Oceanography 30:1078-1083

Wetzel RG (2001) Limnology: Lake and river ecosystems. Academic, Philadelphia, PA.

Yang W, Matsushita B, Chen J, Fukushima T (2011) Estimating constituent concentrations in case II waters from MERIS satellite data by semi-analytical model optimizing and look-up tables. Remote Sensing of Environment 115:1247-1259

Zhang Y, Qin B, Chen W. Zhu G (2005) Preliminary Study of Chromophoric Dissolved Organic Matter (CDOM) in Lake Taihu, a Shallow Subtropical Lake in China, Acta hydrochim. hydrobiol. 33(4):315-323

Zhang Y, Qin B, Hu W, Wang S, Chen Y, Chen W (2006) Temporal-spatial variations of euphotic depth of typical lake regions in Lake Taihu and its ecological environmental significance. Science in China: Series D Earth Sciences 49(4):431-442 
771

772

773

774

775

776

777

778

779

780

781

782

783

784

785

786

787

788

789

790

791

792

793

794

795

796

797

798

799

800

801

802

803

804

805

806

807

Table legends

Table 1 Characteristics of investigated lakes ( ${ }^{a}$ Urabe et al. 1999; ${ }^{b}$ Havens et al. 2001; ${ }^{\mathrm{c}}$ Kagami et al. 2006; ${ }^{\mathrm{d}}$ Goto et al. 2008; ${ }^{\mathrm{e}}$ Oyama et al. 2009)

Table 2 Monitored data and their measurement methods

Table $3 \mathrm{a}^{+}(440)$ and $e^{\prime}$ for the additional measurements

\section{Table 4 SIOPs fitting equations}

Table 5 Model coefficients related to the respective OAS concentrations and values of evaluation indices for the long-term monitoring data using the statistical approach in the two lakes. The coefficients include 95\% confidence intervals [in brackets] and $p$-values ( ${ }^{\text {NS}}$ : non- significant, ${ }^{*} p<0.01, * * p<0.0001$ ).

Table 6 ANOVA results for yearly, monthly and station effects on the mechanistic estimation of $\mathrm{SD}^{-1} . p$-values $(* * p<0.0001)$

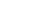

(1)

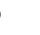

8

(1)

(1)

2

4


808 Table 1 Characteristics of investigated lakes ( ${ }^{a}$ Urabe et al. 1999; ${ }^{b}$ Havens et al. 2001;

$809 \quad{ }^{\mathrm{C}}$ Kagami et al. 2006; ${ }^{\mathrm{d}}$ Goto et al. 2008; ${ }^{\mathrm{e}}$ Oyama et al. 2009)

\begin{tabular}{|c|c|c|c|c|c|c|c|}
\hline Characteristics & Unit & \multicolumn{3}{|c|}{ Lake Biwa northern basin } & \multicolumn{3}{|c|}{ Lake Kasumigaura } \\
\hline Description & & \multicolumn{3}{|c|}{ mesotrophic, monomictic $^{a}$} & \multicolumn{3}{|c|}{ eutrophic, polymictic $^{e}$} \\
\hline $\begin{array}{l}\text { Dominating } \\
\text { phytoplankton } \\
\text { species }\end{array}$ & & \multicolumn{3}{|c|}{$\begin{array}{l}\text { Spring: diatoms }{ }^{\mathrm{d}} \\
\text { Summer: green algae , blue-green algae }{ }^{\mathrm{c}} \\
\text { Autumn: green algae, blue-green algae }^{\mathrm{c}} \\
\text { Winter: diatoms }{ }^{\mathrm{d}}\end{array}$} & \multicolumn{3}{|c|}{$\begin{array}{l}\text { Spring: diatoms } \\
\text { Summer: blue-green } \\
\text { Autumn: diatoms } \\
\text { Winter: diatoms }\end{array}$} \\
\hline Surface area & $\mathrm{km}^{2}$ & \multicolumn{3}{|l|}{$616^{\mathrm{a}}$} & \multicolumn{3}{|l|}{$171^{\mathrm{e}}$} \\
\hline Mean depth & $\mathrm{m}$ & \multicolumn{3}{|l|}{$45.5^{\mathrm{a}}$} & \multicolumn{3}{|l|}{$4.0^{\mathrm{e}}$} \\
\hline Mean total nitrate & $\mu \mathrm{gl}^{-1}$ & \multicolumn{3}{|l|}{$300^{c}$} & \multicolumn{3}{|l|}{$1095^{\mathrm{b}}$} \\
\hline Mean total phosphorous & $\mu \mathrm{gl}^{-1}$ & \multicolumn{3}{|l|}{$1^{\mathrm{c}}$} & \multicolumn{3}{|l|}{$75^{\mathrm{b}}$} \\
\hline \multirow[t]{2}{*}{ Residence time } & year & \multicolumn{3}{|l|}{$5^{\mathrm{a}}$} & \multicolumn{3}{|l|}{$0.6^{\mathrm{e}}$} \\
\hline & & Mean & Min & Max & Mean & Min & $\operatorname{Max}$ \\
\hline SD & $\mathrm{m}$ & 5.73 & 0.9 & 13.2 & 0.64 & 0.15 & 3.8 \\
\hline Chl-a concentration & $\mu \mathrm{gl}^{-1}$ & 3.5 & 0.2 & 69 & 63.9 & 1 & 352 \\
\hline TSS concentration & $\mathrm{mgl}^{-1}$ & 1.5 & 0.6 & 42 & 23.5 & 1.4 & 118.3 \\
\hline DOC concentration & $\mathrm{mgl}^{-1}$ & 1.26 & 0.8 & 2.1 & 3.17 & 1.2 & 7.7 \\
\hline
\end{tabular}

810

811

812

813

814

815

816

817

818

819

820

821

822

823

824

825

826

827

828

829

830

831

832

833 
834 Table 2 Monitored data and their measurement methods

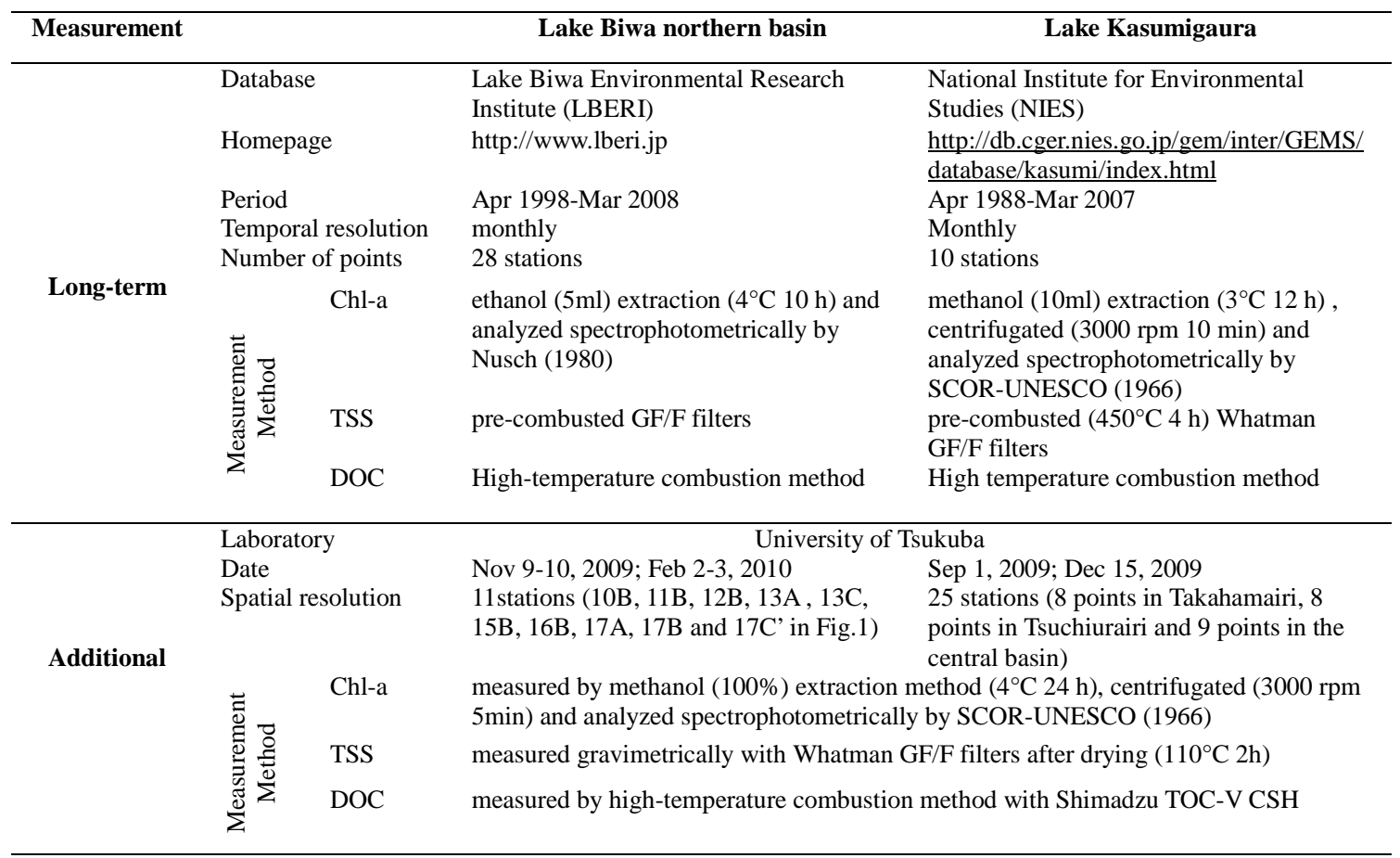

835

836

837

838

839

840

841

842

843

844

845

846

847

848

849

850

851

852

853

854

855 
856 Table $3 \mathrm{a}^{+}(440)$ and $e^{\prime}$ for the additional measurements

\begin{tabular}{lccc}
\hline Lake & [DOC] $\left(\mathbf{m g ~ l}^{-1}\right)$ & $\mathbf{a}^{+}(\mathbf{4 4 0})\left(\mathbf{l m g}^{-1} \mathbf{m}^{-1}\right)$ & $\left.\boldsymbol{e}^{\prime} \mathbf{( m}^{-1}\right)$ \\
\hline Biwa & $1.3-1.7$ & $0.08-0.18$ & $0.01-0.19$ \\
Kasumigaura & $3.7-5.4$ & $0.22-0.55$ & $0.05-0.87$ \\
\hline
\end{tabular}

857

858

859

860

861

862

863

864

865

866

867

868

869

870

871

872

873

874

875

876

877

878

879

880

881

882

883

884

885

886

887

888

889

890 
891

Table 4 SIOPs fitting equations

\begin{tabular}{|c|c|c|c|c|c|c|}
\hline \multirow{2}{*}{ Equation } & \multirow{2}{*}{ Reference } & \multirow{2}{*}{$\begin{array}{l}\text { Fitting } \\
\text { factor }\end{array}$} & \multicolumn{2}{|c|}{ Lake Biwa } & \multicolumn{2}{|c|}{ Lake Kasumigaura } \\
\hline & & & $\begin{array}{c}\text { Nov 9-10, } \\
2009 \\
\end{array}$ & $\begin{array}{c}\text { Feb 2-3, } \\
2010\end{array}$ & $\begin{array}{c}\text { Sep 1, } \\
2009\end{array}$ & $\begin{array}{c}\text { Dec 15, } \\
2009\end{array}$ \\
\hline $\mathbf{a}_{\text {CDOM }}^{*}(\lambda)=\exp \left[-S_{\text {CDOM }}(\lambda-440)\right]$ & Gege (2004) & $\mathrm{S}_{\mathrm{CDOM}}$ & 0.007 & 0.008 & 0.008 & 0.009 \\
\hline & Giardino et & $\mathrm{S}_{\mathrm{NPSS}}$ & 0.004 & 0.002 & 0.006 & 0.007 \\
\hline $\mathrm{a}_{\mathrm{NPSS}}(\lambda)=\mathrm{a}_{\mathrm{NPSS}}(440) \cdot \exp \left[-\mathrm{S}_{\mathrm{NPSS}}(\lambda\right.$ & al. (2007) & $\mathrm{a}_{\mathrm{NPSS}}^{*}(440)$ & 0.264 & 0.164 & 0.129 & 0.286 \\
\hline $\mathbf{h}^{*} \quad(\lambda)-\mathbf{h}^{*} \quad(660) \cdot[\lambda]^{-\mathbf{n}}$ & Reinart et al. & $\mathrm{b}_{\mathrm{NPSS}}^{*}(660)$ & 0.546 & 0.661 & 0.419 & 0.393 \\
\hline $\mathbf{b}_{\text {NPSS }}(\lambda)=b_{\text {NPSS }}(660) \cdot|\overline{660}|$ & $(2004)$ & $\mathrm{n}$ & 0.711 & 0.538 & 0.864 & 0.704 \\
\hline
\end{tabular}

892

S: Slope parameter of absorption curve

893

894

895

896

897

898

899

900

901

902

903

904

905

906

907

908

909

910

911

912

913

914

915

916

917

918

919

920

921

922

923 
924 Table 5 Model coefficients related to the respective OAS concentrations and values of 925 evaluation indices for the long-term monitoring data using the statistical approach in the 926 two lakes. The coefficients include 95\% confidence intervals [in brackets] and $p$-values $927 \quad$ ( ${ }^{\mathrm{NS}}$ : non- significant, $\left.{ }^{*} p<0.01,{ }^{* *} p<0.0001\right)$.

\begin{tabular}{|c|c|c|c|c|c|c|}
\hline Lake & $\begin{array}{c}\text { Chl-a coeff. } \\
\left(\mathrm{ug}^{-1} \mathbf{l m}^{-1}\right)\end{array}$ & $\begin{array}{l}\text { NPSS coeff. } \\
\left(\mathrm{mg}^{-1} \mathbf{l m}^{-1}\right)\end{array}$ & $\begin{array}{c}\text { DOC coeff. } \\
\left(\mathrm{mg}^{-1} \mathrm{~lm}^{-1}\right)\end{array}$ & $\begin{array}{c}\text { Water } \\
\left(\mathrm{m}^{-1}\right)\end{array}$ & $R^{2}$ & $\begin{array}{c}\text { RMSE } \\
\left(\mathbf{m}^{-1}\right)\end{array}$ \\
\hline $\begin{array}{c}\text { Biwa } \\
(N=3696)\end{array}$ & $\begin{array}{c}0.0137^{* *} \\
{[0.013,0.015]}\end{array}$ & $\begin{array}{c}0.100^{* *} \\
{[0.097,0.102]}\end{array}$ & $\begin{array}{c}0.031^{* *} \\
{[0.022,0.039]}\end{array}$ & $\begin{array}{c}0.040^{* *} \\
{[0.026,0.047]}\end{array}$ & 0.70 & 0.05 \\
\hline \multirow{2}{*}{$\begin{array}{c}\text { Kasumigaura } \\
(N=2280)\end{array}$} & $\begin{array}{c}0.0080 * * \\
{[0.0074,0.0087]}\end{array}$ & $\begin{array}{c}0.040 * * \\
{[0.038,0.042]}\end{array}$ & $\begin{array}{c}0.010^{\mathrm{NS}} \\
{[-0.01,0.03]}\end{array}$ & $\begin{array}{c}0.680^{*} \\
{[0.59,0.75]}\end{array}$ & 0.62 & 0.39 \\
\hline & $\underline{0.0086 * *}$ & $\underline{0.043 * *}$ & $\underline{0.170 * *}$ & $\underline{0.055}$ & $\underline{0.60}$ & $\underline{0.41}$ \\
\hline
\end{tabular}

928

$\bar{N}$ : number of measurements; underlined values correspond to the ones after correction of the water coefficient (see the text).

929

930

931

932

933

934

935

936

937

938

939

940

941

942

943

944

945

946

947

948

949

950

951

952

953

954

955

956 
957 Table 6 ANOVA results for yearly, monthly and station effects on the mechanistic 958 estimation of $\mathrm{SD}^{-1} . p$-values $(* * p<0.0001)$

\begin{tabular}{lccccc} 
& \multicolumn{6}{c}{ SS } & $\boldsymbol{d} \boldsymbol{f}$ & $\boldsymbol{M S}$ & $\boldsymbol{F}$ & $\boldsymbol{p}$-value \\
\hline Year & 24.64 & 10 & 2.46 & 72.07 & $* *$ \\
Month & 35.76 & 11 & 3.25 & 95.09 & $* *$ \\
Station & 53.23 & 26 & 2.05 & 59.88 & $* *$ \\
Year * Month & 51.85 & 110 & 0.47 & 13.79 & $* *$ \\
Year * Station & 14.73 & 260 & 0.06 & 1.66 & $* *$ \\
Month * Station & 17.95 & 286 & 0.06 & 1.84 & $* *$ \\
Error & 97.78 & 2860 & 0.03 & & \\
Total & 295.94 & 3563 & & & \\
\hline
\end{tabular}

\begin{tabular}{ccccc}
\hline \multicolumn{5}{c}{ Lake Kasumigaura } \\
$\boldsymbol{S} \boldsymbol{S}$ & $\boldsymbol{d} \boldsymbol{f}$ & $\boldsymbol{M} \boldsymbol{S}$ & $\boldsymbol{F}$ & $\boldsymbol{p}$-value \\
\hline 19.54 & 18 & 1.09 & 52.22 & $* *$ \\
15.89 & 11 & 1.44 & 69.49 & $* *$ \\
6.95 & 9 & 0.77 & 37.14 & $* *$ \\
44.21 & 198 & 0.22 & 10.74 & $* *$ \\
5.36 & 162 & 0.03 & 1.59 & $* *$ \\
4.90 & 99 & 0.05 & 2.38 & $* *$ \\
37.05 & 1782 & 0.02 & & \\
133.90 & 2279 & & & \\
\hline
\end{tabular}

959

$S S$ : Sum of squares; $d f$ : Degrees of freedom; $M S$ : Mean of squares; and F: Test statistic value

960

961

962

963

964

965

966

967

968

969

970

971

972

973

974

975

976

977

978

979

980

981

982

983

984

985

986

987 
990 Fig. 1 Locations of two lakes and long-term sampling stations (closed circles).

991 Fig. 2 Phytoplanktonic SIOPs in Lakes Biwa and Kasumigaura: (a) specific absorption 992 coeff. $\mathrm{a}^{*} \mathrm{ph}(\lambda)$; and (b) specific scattering coeff. $\mathrm{b}^{*} \mathrm{ph}(\lambda)$.

993 Fig. 3 Time series of annual conditions of SD and OAS concentrations in Lake Biwa 994 (a,b,c,d) and Lake Kasumigaura (e,f,g,h). Horizontal lines within boxes show median 995 values, boxes show 25-75\% data ranges, whiskers show minimum and maximum values, 996 and open circles indicate mean values.

997 Fig. 4 Statistical model performance (measured vs. predicted reciprocal of SD) for the 998 long-term dataset. Solid lines represent linear regression curves and dotted line denotes $999 \quad$ 1:1 prediction line.

1000 Fig. 5 Mechanistic model performance (measured vs. predicted reciprocal of SD) for 1001 long-term dataset. Solid lines represent linear regression curves and dotted line denotes $1002 \quad$ 1:1 prediction line.

1003 Fig. 6 OAS contributions on $\mathrm{SD}^{-1}$ values (a) Lake Biwa and (b) Lake Kasumigaura 1004 Fig. 7 Mean ( \pm Standard deviation) of the ratios of measured vs. predicted SD $^{-1}$ 1005 estimated over years, months and stations using the mechanistic model for Lake Biwa 1006 (a,b,c) and Lake Kasumigaura (d,e,f), respectively.

1007 Fig. 8 Coefficient of determination $R^{2}$ of statistical models using temporal and spatial 1008 grouping of long-term datasets. The open circles correspond to Lake Biwa, and the closed 1009 circles to Lake Kasumigaura. The dashed and solid lines are the $R^{2}$ values using whole 1010 datasets of Lakes Biwa and Kasumigaura, respectively. 


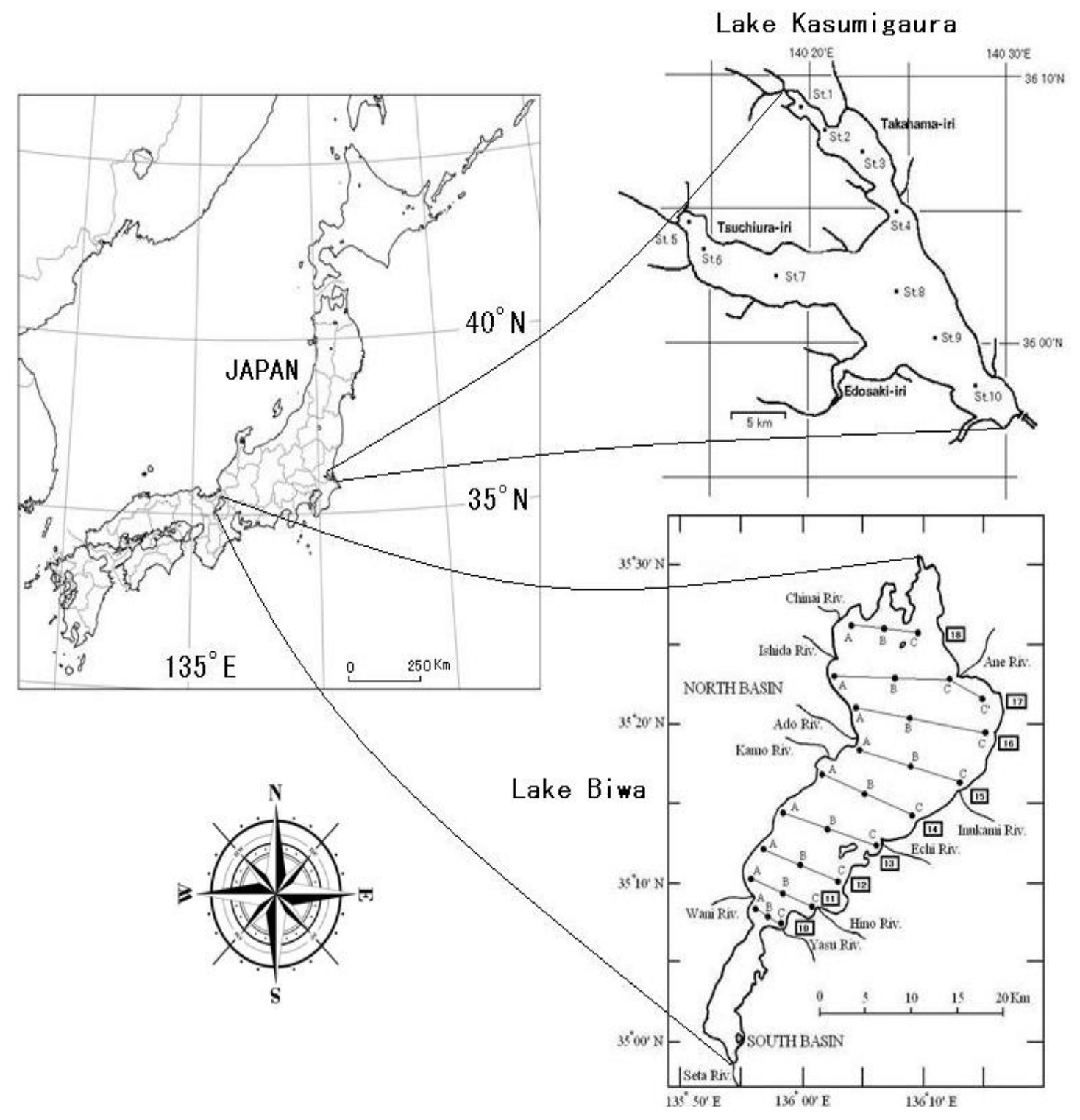

1013

Fig. 1 Locations of two lakes and long-term sampling stations (closed circles).

1015

1016

1017

1018

1019

1020

1021

1022

1023

1024

1025

1026 
(a)

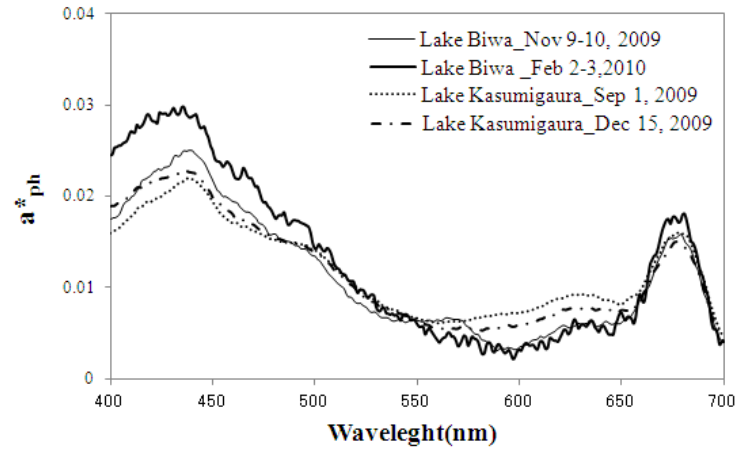

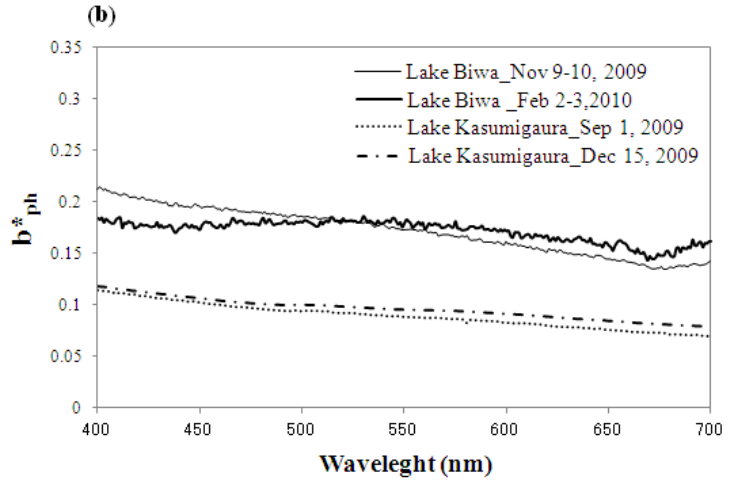

1027

1028

1029

1030

1031

1032

1033

1034

1035

1036

1037

1038

1039

1040

1041

1042

1043

1044

1045

1046

1047

1048

1049

1050

1051

1052

1053

1054

1055

Fig. 2 Phytoplanktonic SIOPs in Lakes Biwa and Kasumigaura: (a) specific absorption coeff. a*ph $(\lambda)$; and (b) specific scattering coeff. $b^{*}$ ph $(\lambda)$. 

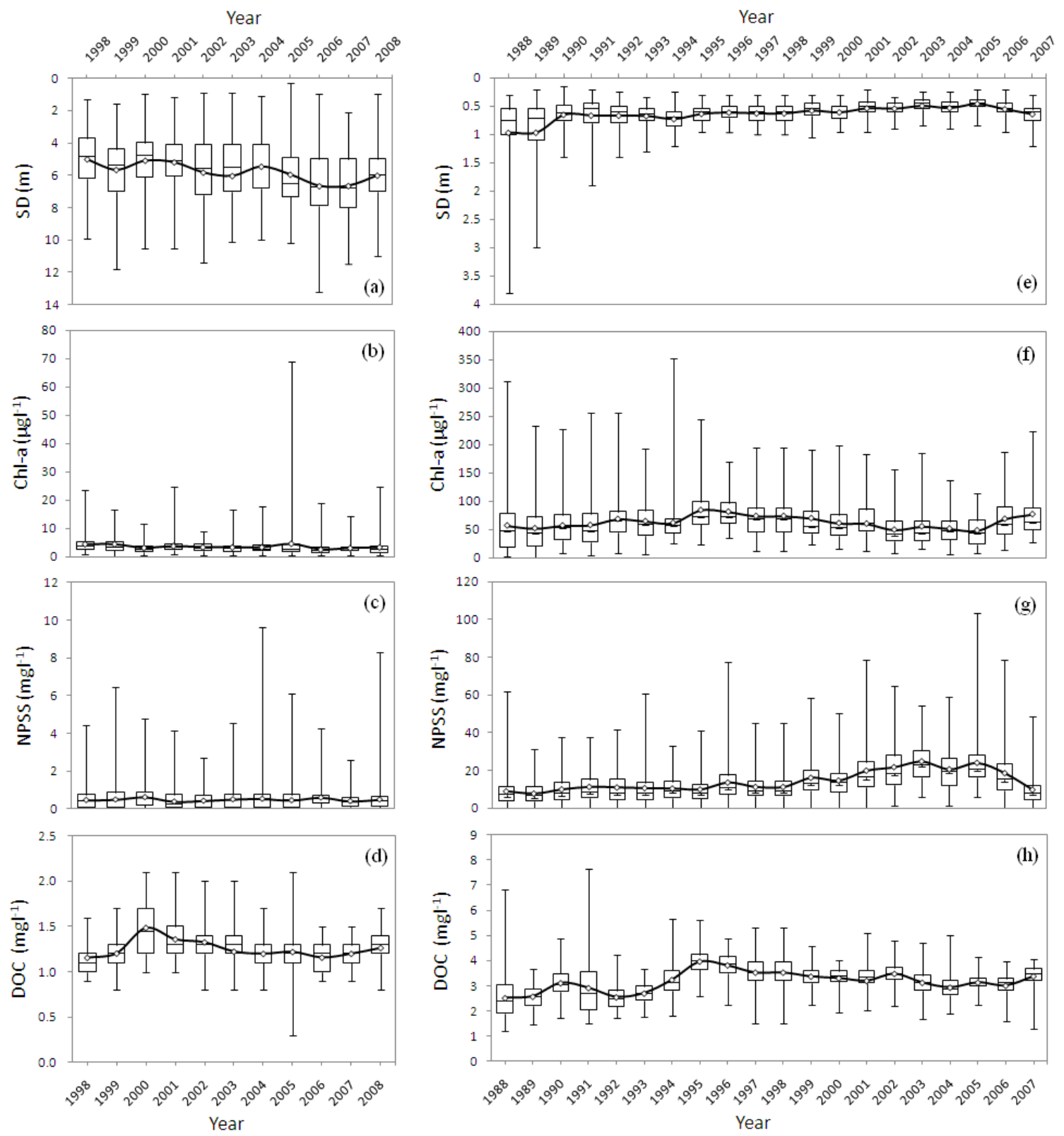

Fig. 3 Time series of annual conditions of SD and OAS concentrations in Lake Biwa (a,b,c,d) and Lake Kasumigaura (e,f,g,h). Horizontal lines within boxes show median values, boxes show $25-75 \%$ data ranges, whiskers show minimum and maximum values, and open circles indicate mean values.

1061

1062

1063

1064

1065

1066

1067 
(a) Lake Biwa

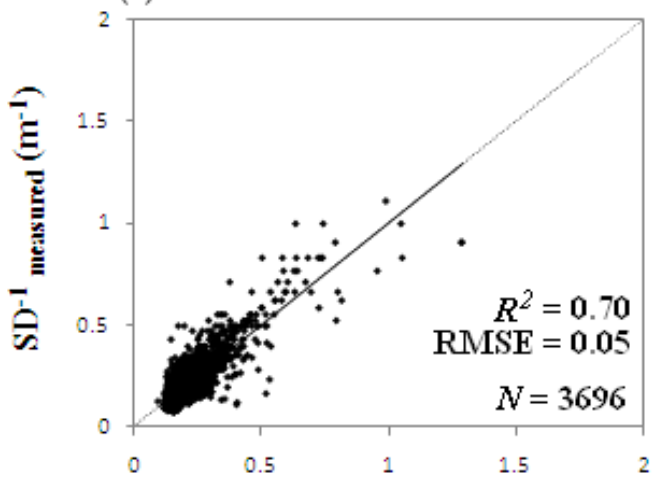

(b) Lake Kasumigaura

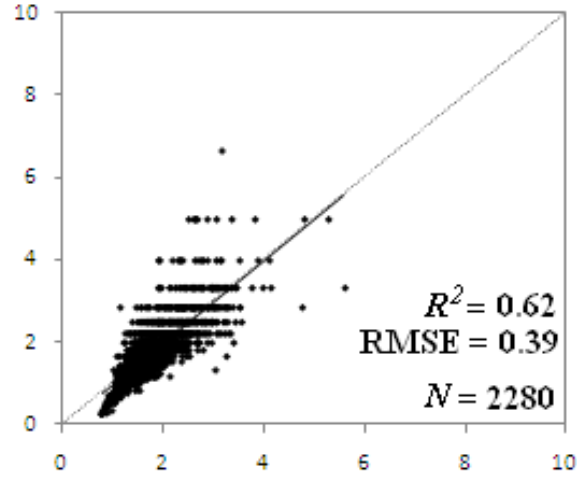

1068

1069

1070

1071

1072

1073

1074

1075

1076

1077

1078

1079

1080

1081

1082

1083

1084

1085

1086

1087

1088

1089

1090

1091

1092

1093

1094

$\mathrm{SD}^{-1}$ predicted $\left(\mathrm{m}^{-1}\right)$

Fig. 4 Statistical model performance (measured vs. predicted reciprocal of SD) for the long-term dataset. Solid lines represent linear regression curves and dotted line denotes 1:1 prediction line.

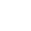

(1)


(a) Lake Biwa

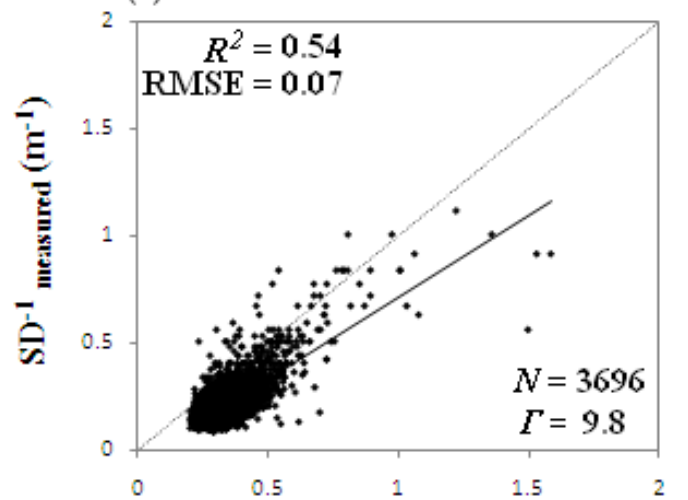

(b) Lake Kasunigaura

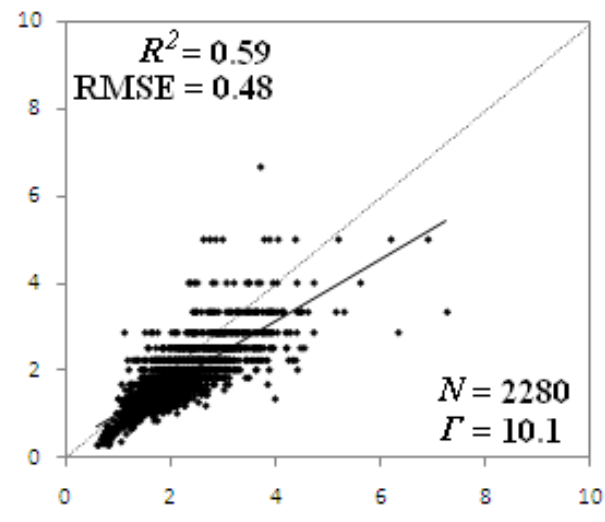

1095 $\mathrm{SD}^{-1}$ predicted $\left(\mathrm{m}^{-1}\right)$

1096 Fig. 5 Mechanistic model performance (measured vs. predicted reciprocal of SD) for 1097 long-term dataset. Solid lines represent linear regression curves and dotted line denotes 1:1 prediction line.

1099

1100

1101

1102

1103

1104

1105

1106

1107

1108

1109

1110

1111

1112

1113

1114

1115

1116

1117

1118

1119 
(a) Lake Biwa

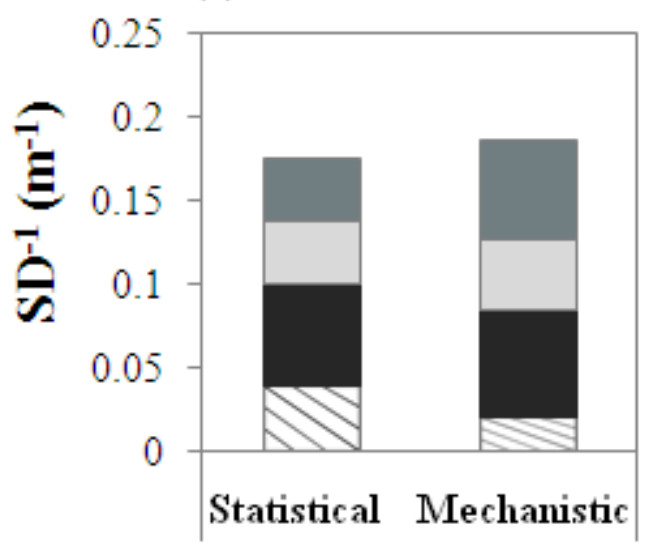

(b) Lake Kasumigaura

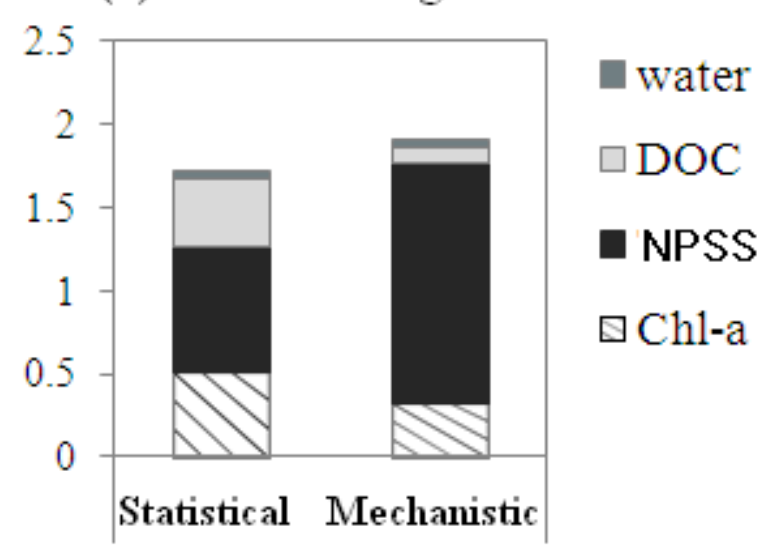

1120

1121

1122

1123

1124

1125

1126

1127

1128

1129

1130

1131

1132

1133

1134

1135

1136

1137

1138

1139

1140

1141

1142

1143

1144

1145

1146

1147

Fig. 6 OAS contributions on $\mathrm{SD}^{-1}$ values (a) Lake Biwa and (b) Lake Kasumigaura. 
(a)

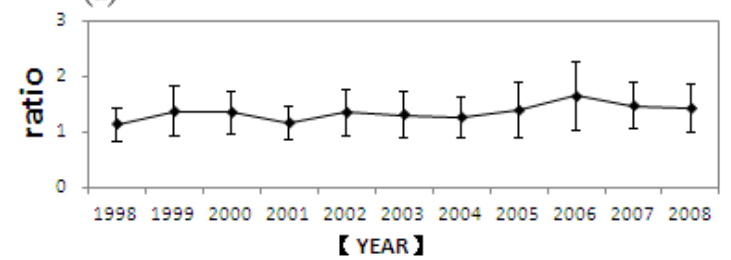

(c)

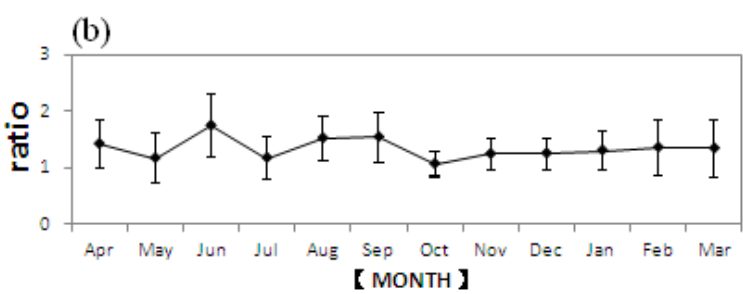

【MONTH 】

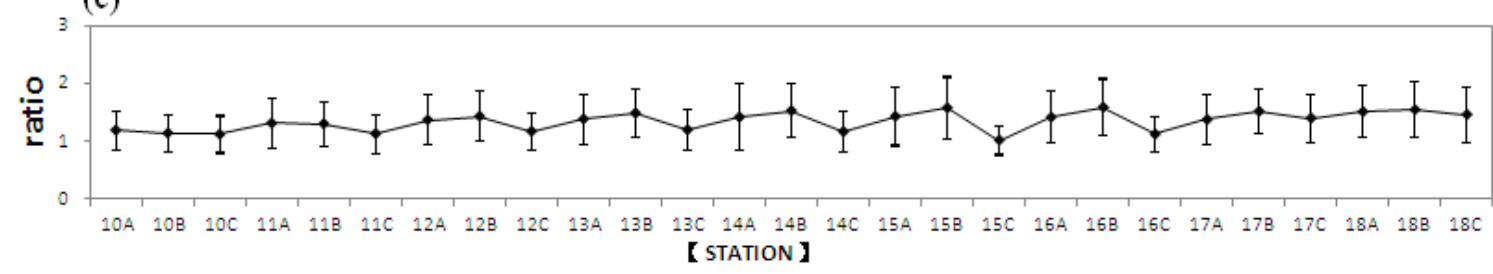

(d)

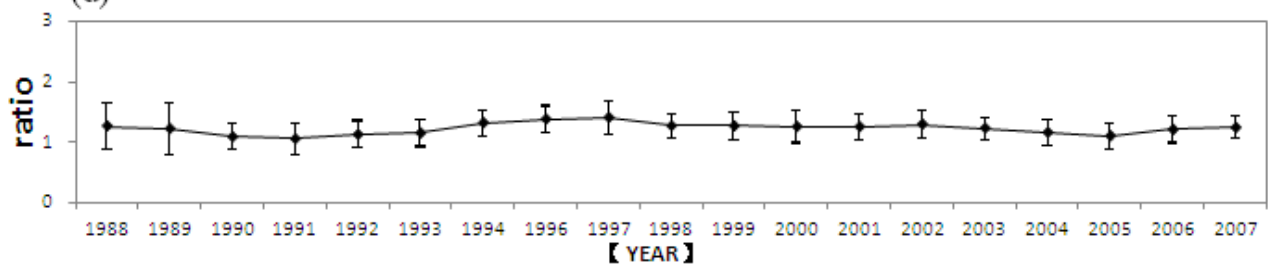
(e)
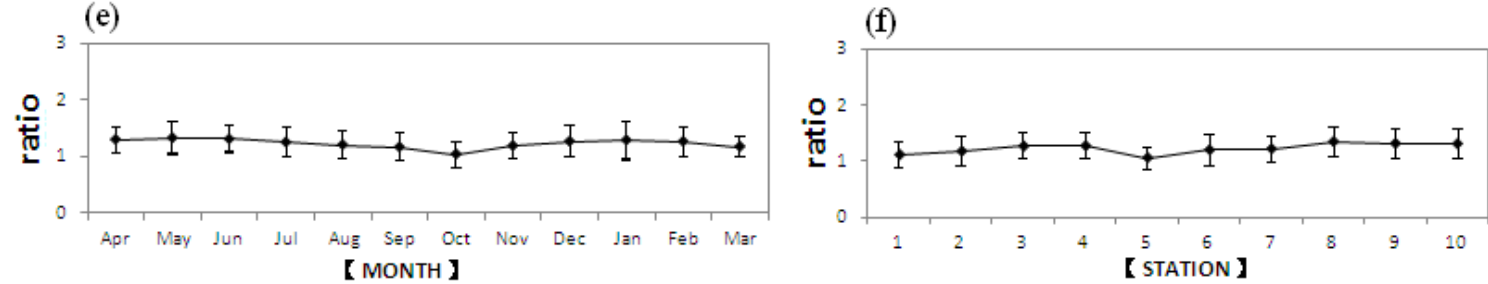

1148

1149

1150

1151

1152

1153

1154

1155

1156

1157

1158

1159

1160

1161

1162

1163

1164

1165

Fig. 7 Mean ( \pm Standard deviation) of the ratios of measured vs. predicted $\mathrm{SD}^{-1}$ estimated over years, months and stations using the mechanistic model for Lake Biwa (a,b,c) and Lake Kasumigaura (d,e,f), respectively. 
(a) Yearly

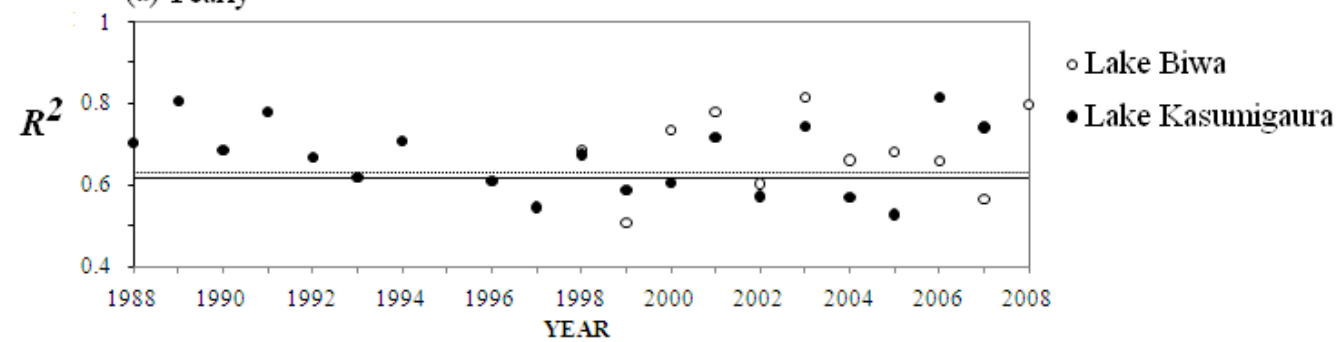

(b) Monthly

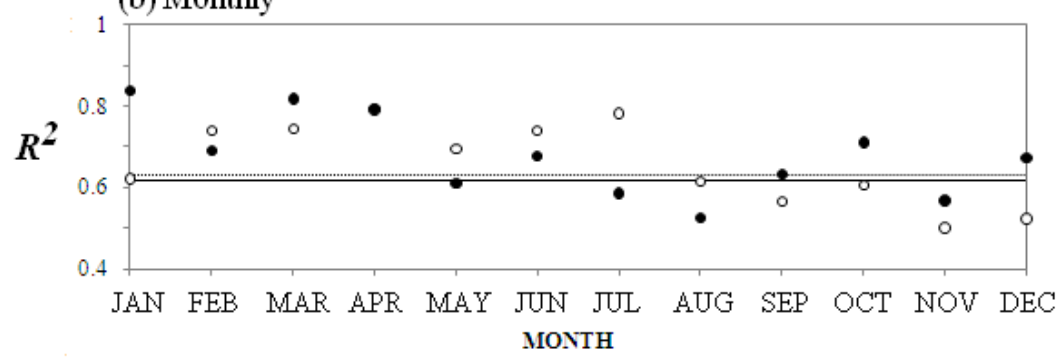

(c) Spatially

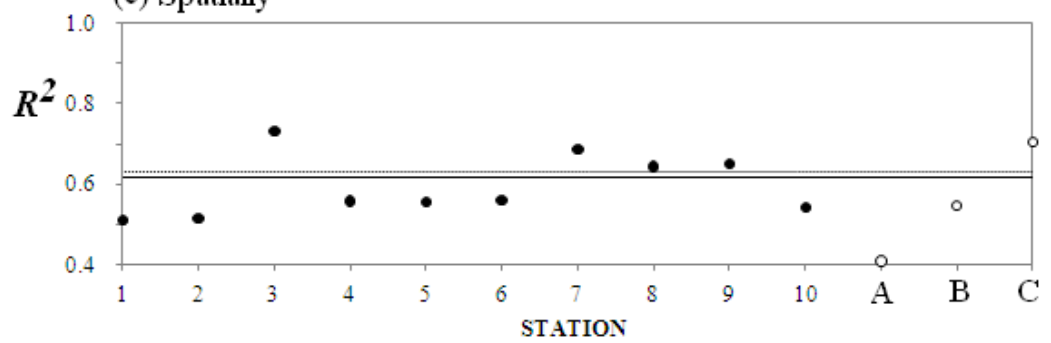

1166

1167 Fig. 8 Coefficient of determination $R^{2}$ of statistical models using temporal and spatial 1168 grouping of long-term datasets. The open circles correspond to Lake Biwa, and the closed 1169 circles to Lake Kasumigaura. The dashed and solid lines are the $R^{2}$ values using whole 1170 datasets of Lakes Biwa and Kasumigaura, respectively. 